\title{
Tuberculous Encephalopathy Mimicking Limbic Encephalitis and Large Intraparenchymal Mass: A Challenge In Diagnosis
}

Raihanah Haroon ${ }^{1}$, Siti Kamariah Che Mohamed ${ }^{1}$, Radhiana Hassan ${ }^{1}$

${ }^{1}$ Department of Radiology, Kulliyyah of Medicine, International Islamic University of Malaysia

Presenter: Raihanah Haroon

Tuberculosis of central nervous system (CNS TB) being endemic in Malaysia, most commonly presents as tuberculoma or meningitis. Less commonly, this specific disease entity presents as cerebritis, miliary form, encephalitis and large intraparenchymal mass. At the cellular level, it was even postulated that the pathogenesis of the most common form of CNS TB is way different from the rarer form of encephalitis. Parenchymal involvement of CNS TB is primarily believed as a result of leptomeningeal/ ependymal extension or gross occlusion of basal arteries due to exudates and arteritis. However, the pathogenesis of TB encephalitis was postulated to result from type IV direct (allergic type) hypersensitivity which is similar to other demyelinating diseases at present. Here, we highlight an extremely rare imaging manifestation of CNS TB, which impersonates limbic encephalitis and large intraparenchymal mass imposing a diagnostic dilemma. 